\section{Finding answers from the seas}

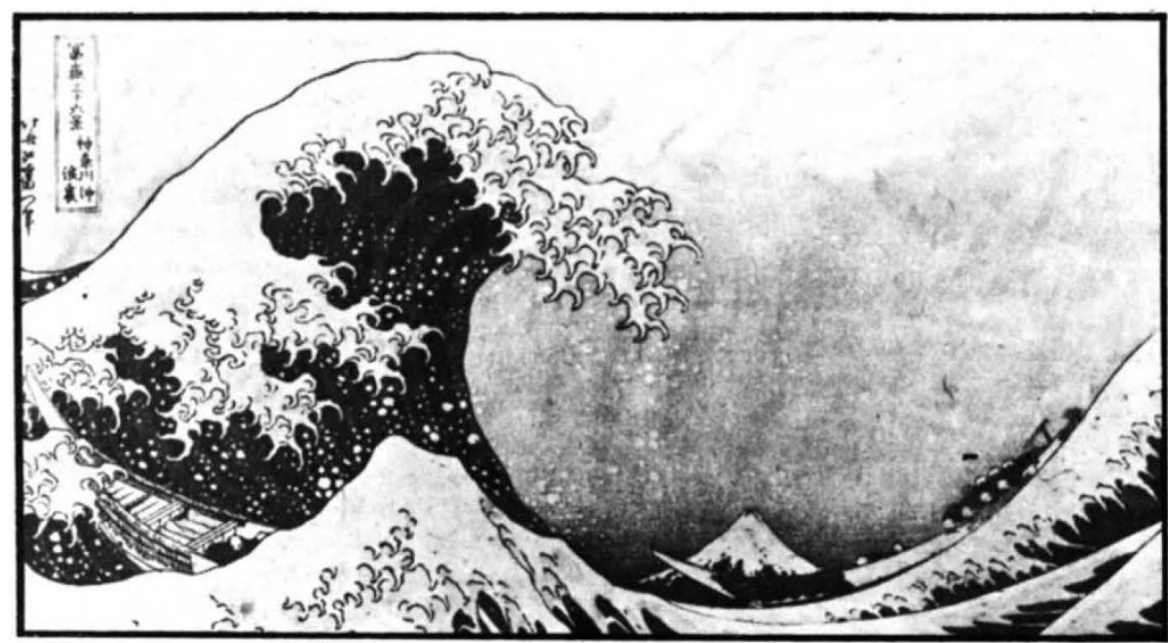

The Sea: Ideas and Observations on Progress in The Study of The Sea. Vol. 5: Marine Chemistry. Edited by E. D. Goldberg. Pp. xiv +895 . (Wiley-Interscience: New York and London, June 1974.) $£ 21.20$.

AT the First International Oceanographic Congress in New York in 1959, Lars Gunnar Sillén, Professor of Inorganic Chemistry at the Royal Institute of Technology in Stockholm, was invited to express the views of a laboratory chemist on the composition of sea water. His lecture, "The Physical Chemistry of Sea Water" represents a milestone in the development of ideas about the chemistry of sea water and the evolution of the composition of the hydrosphere, atmosphere and lithosphere over geological time. As Goldberg points out, the lecture was, in fact, the first of a series of investigations of the implications of equilibrium calculations of the ocean system, which challenged many prevailing notions and provided new ideas about a wide range of natural phenomena.

Volume 5 of The Sea is dedicated to Sillén and consists of accounts of the status of specific aspects of marine chemical research and includes chapters on completely new growth areas which have developed since Sillén's passing.

The status reports are largely contained in Part I (Thermodynamics of the Seawater System) and Part III (The Sedimentary Cycle). Millero, Disteche, Dyrrsen and Wedborg review the purely thermodynamic aspects of sea water as an electrolyte solution. Gieskes discusses the alkalinity $/ \mathrm{CO}_{2}$ problem, and confirms the confusion that arises over the use of apparent constants to describe the $\mathrm{CO}_{2}$ system in the sea. That chapter is particularly refreshing because in addition to thermodynamic and kinetic considerations, mention is made of the influence of both sediments and purely physical oceanographical processes on the distribution of $\mathrm{CaCO}_{3}$ and some other chemical parameters in the sea. Breck reiterates his own suggestion that the $p E$ (the redox potential) in oxic seawater is governed by the $\mathrm{O}_{2} / \mathrm{H}_{2} \mathrm{O}_{2}$ couple and has a value substantially different from that estimated by Sillén.

Part III is by far the largest section of the book, and starts off with a chapter by Garrels (who specifically mentions the effect of Sillén's 1959 lecture on the direction of his own research) and Perry. It is a brief summary of the main conclusions of several papers by Garrels and his coworkers, and of the book Evolution of Sedimentary Rocks by Garrels and Mackenzie (1971). The section also has two interesting and quite different chapters on specific problems in sedimentary geochemistry, namely magnesium (Drever) and silicon (Wollast). Chapters on diagenesis (Berner), interstitial waters (Manheim and Sayles) and sulphur (Goldhaber and Kaplan) emphasise the large amount of attention currently directed towards post-depositional reactions in unconsolidated sediments, reactions which are important in controlling the long-term composition of sea water itself.

In Part IV (The Impact of Life Processes Excluding Man), Menzel gives a timely, if partisan, review of the mass of conflicting data on the distribution of dissolved and particulate carbon in the sea, and its metabolic fate. A large amount of data obtained about 10 years ago, which was treated with some scepticism when it first appeared, is apparently reliable so that some early, hotly debated, suggestions about the carbon cycle are probably correct. The relatively new area of the chemistry of marine natural products is reviewed in depth by Faulkner and Andersen, and Lowenstam offers a lengthy account of the information available on the chemical composition of inorganic skeletal material and the impact of skeleton building on other chemical and physical processes in the oceans.

Part V (The Impact of Man on the Chemistry of the Oceans) is remarkably short in view of current interest (albeit concern) in the topic and the influence that the editor has himself had in drawing attention to it. The chapter by Jernelöv on heavy metals, metalloids and synthetic organics is very brief and inadequately referenced, and that by Preston dealing with artificial radioactivity is simply an inventory and a straightforward account of the possible behaviours of important radionuclides. Part VI (Origin of the Ocean) contains a single chapter by Arrhenius, De and Alfvén, which reviews their own recent work in several far flung branches of space research.

The most interesting contributions in this large volume are, however, contained in Part II (Air-Sea Interactions). They are interesting because they are concerned with new growth areas in marine chemistry. Thus, MacIntyre presents an iconoclastic, in places amusing, and thorough review of reactions in the sea-surface microlayer using a mass of data drawn from sources not immediately available, or indeed obvious, to marine scientists. Seiler and Schmidt, in a refreshing account of non-conservative gases in the sea, point out that the main source of nitrous oxide in the atmosphere is in fact the ocean, and that the atmospheric budgets for hydrogen, methane and carbon monoxide are affected to important degrees by processes in the sea.

This volume, although it is an invaluable addition to the series, does have some deficiencies. Specifically, the success or otherwise of the ion association and specific interaction models in describing the properties of sea water electrolytes is passed over rather swiftly. Recent work by Whitfield, Leyendekkers and Pytkowicz, for example, has given interesting new insight into the utility of some of the available models. A second almost completely neglected area which is only mentioned somewhat obliquely by Gieskes and Menzel, concerns the currently popular use of advectiondiffusion models to describe and to understand the distribution of certain chemical parameters in the oceans. Whatever one may think of the usefulness of this particular approach, it has focused some much needed attention on some of the hidden effects that physical and biological processes have on the behaviour of some of the variables frequently measured by marine chemists. S. E. Calvert 